Drożak Paulina, Augustowska Katarzyna, Bryliński Lukasz, Bura Agata, Drożak Martyna, Duda Piotr, Rudnicka-Drożak Ewa. Adverse Childhood Experiences as a significant predictor of worsened well-being among Polish medical and dental students. Journal of Education, Health and Sport. 2021;11(7):175-184. eISSN 2391-8306. DOI http://dx.doi.org/10.12775/JEHS.2021.11.07.016

https://apcz.umk.pl/czasopisma/index.php/JEHS/article/view/JEHS.2021.11.07.016

https://zenodo.org/record/5136951

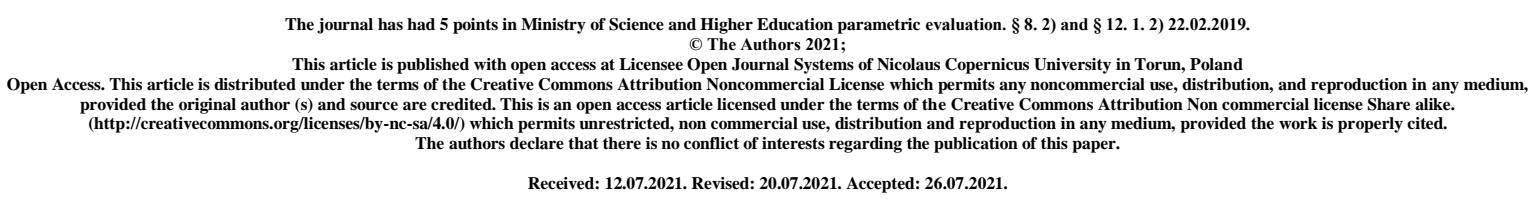

\title{
Adverse Childhood Experiences as a significant predictor of worsened well- being among Polish medical and dental students
}

\author{
Paulina Drożak', Katarzyna Augustowska', Lukasz Bryliński', Agata Bura ${ }^{1}$, \\ Martyna Drożak ${ }^{1}$, Piotr Duda ${ }^{1}$, Ewa Rudnicka-Drożak ${ }^{2}$ \\ 1. Students' Scientific Association of Chair and Department of Family Medicine, \\ Medical University of Lublin. \\ 2. Chair and Department of Family Medicine, Medical University of Lublin.
}

\begin{abstract}
Introduction and purpose. Adverse Childhood Experiences (ACEs) are a major public health problem. The aim of the study was to investigate the prevalence of Adverse Childhood Experiences among medical and dental students in Poland and to examine a relationship between ACEs and chosen factors associated with well-being of the students.
\end{abstract}

Material and method. The research tool consisted of the Adverse Childhood Experiences standardized questionnaire and authors' questions. 934 medical students and 228 dental students took part in the study (a total of 1162 participants). The respondents came from 18 Polish universities.

Results. $57.40 \%$ of the students experienced at least 1 childhood adversity, $8.43 \%$ of them were affected by 4 or more ACEs. The most common adverse childhood experiences were: emotional neglect $(23.06 \%)$, emotional abuse $(22.98 \%)$ and mental illness or a suicide attempt in a household member $(21.86 \%)$. On average, women experienced more childhood adversities than men. An overall graded relationship was found between ACEs and: frequent feelings of loneliness, low self-assessment of academic performance, problems with maintaining stable body weight, reaching for alcohol in order to de-stress and being non-religious.

Conclusions. Adverse Childhood Experiences are common among Polish medical and dental students and are linked with multiple aspects of worsened well-being of the students. The study emphasizes a need to create strategies that aim to educate on Adverse Childhood Experiences in order to prevent them and help those who are affected by them.

Key words: Adverse Childhood Experiences; medical students; dental students. 


\title{
Introduction
}

Adverse Childhood Experiences (ACEs) are a major public health problem. They are the 10 types of the most common potentially traumatic events that can happen to a child under 18 years of age. ACEs are grouped into 3 domains that contain a total of 10 categories: abuse (emotional, physical and sexual), neglect (emotional and physical) and household dysfunctions (mental illness in a household member, physical violence towards mother, substance abuse in a household member, parental separation or divorce and imprisonment of a household member) [1].

Exposure of a child to stressors, such as ACEs, can lead to toxic stress response which results from dysregulation of neuroendocrine and immune systems which affects many systems of the body leading to long-term disturbances of their functioning [2]. Many studies have shown a dose-response relationship between ACEs and multiple physical and mental health problems in adult life, such as: cardiovascular diseases, chronic lung diseases, headaches, autoimmune diseases, obesity, sleeping problems, depression, PTSD, anxiety and early death. Moreover, a relationship was found between ACEs and many aspects of worsened socioeconomic status and negative behaviors in later life, such as: smoking, substance abuse, unemployment, risky sexual behaviors and criminal behaviors $[3,4,5,6]$. It was established that 4 or more ACEs are a strong predictor of poor health [7].

Adverse Childhood Experiences are common among Polish students. A research carried out in 2016 among 1760 Polish students showed that $76.6 \%$ of them experienced at least $1 \mathrm{ACE}$ and $19.22 \%$ of them were affected by 4 or more ACEs. This study included students of 5 universities among which there were no medical universities [8]. To our best knowledge, no study has been conducted on the prevalence of ACEs among Polish medical and dental students.

\begin{abstract}
Aim
The aim of the study was to analyze the prevalence of Adverse Childhood Experiences among medical and dental students in Poland and to investigate a relationship between ACEs and chosen factors associated with well-being of the students.
\end{abstract}

\section{Material and method}

The research tool included the Adverse Childhood Experiences standardized questionnaire and author's questions which concerned sociodemographic characteristics of an investigated group and investigated factors. All questions were closed and single-choice. The author's questions were measured with Likert scale. Answers were collected in the April of 2020. The research tool was placed on official groups dedicated to medical and dental students on Facebook social networking site. The questionnaire was anonymous and participation in the research was voluntary. Collected data was analyzed statistically. To assess a relationship between the two variables, the Chi-square test of independence was used. The level of significance was set at $p$ $<0.05$. 


\section{Results}

\section{Demographic characteristics}

The research was carried out among 1162 participants: $80.38 \%$ of them were medical students $(n=934)$ and $19.62 \%$ of them were dental students $(n=228)$. Among respondents there were students of all of the 18 Polish universities that offer medical education and all of the 10 Polish universities that offer dental education. Women constituted of $76.33 \%$ of the participants $(\mathrm{n}=$ $887)$ and men $-23.67 \%(n=275)$. Among respondents there were students of each year of both medical and dental studies. The age of the respondents ranged from 18 to 34 years, the mean age was $21.71 \pm 1.97$ years, whereas the median age 21 years. $43.20 \%(n=502)$ of the students stated that they often feel lonely. 47.07\% $(\mathrm{n}=547)$ of the students rated their academic performance positively. $60.07 \%(\mathrm{n}=698)$ of the respondents didn't have problems with maintaining stable body weight. $48.62 \%(n=565)$ of the participants stated that they don't reach for alcohol in order to de-stress or discharge negative emotions. $44.66 \%(n=519)$ of the students described themselves as religious. (Table 1).

Table 1. Demographic data of the participants.

\begin{tabular}{|c|c|}
\hline & n (\%) \\
\hline $\begin{array}{l}\text { Course of study } \\
\text { Medicine } \\
\text { Dental medicine }\end{array}$ & $\begin{array}{l}934(80.38 \%) \\
228(19.62 \%)\end{array}$ \\
\hline $\begin{array}{c}\text { Gender } \\
\text { Female } \\
\text { Male }\end{array}$ & $\begin{array}{l}887(76.33 \%) \\
275(23.67 \%)\end{array}$ \\
\hline $\begin{array}{l}\text { Do you often feel lonely? } \\
\text { Definitely yes/ Rather yes } \\
\text { Hard to tell } \\
\text { Definitely not/ Rather not }\end{array}$ & $\begin{array}{l}502(43.20 \%) \\
278(23.92 \%) \\
382(32.87 \%)\end{array}$ \\
\hline $\begin{array}{l}\text { How do you assess your academic } \\
\text { performance? } \\
\text { Very good/good } \\
\text { Average } \\
\mathrm{Bad} / \mathrm{very} \text { bad } \\
\end{array}$ & $\begin{array}{l}547(47.07 \%) \\
492(42.34 \%) \\
123(10.59 \%) \\
\end{array}$ \\
\hline $\begin{array}{l}\text { Do you have problems with maintaining } \\
\text { stable body weight? } \\
\text { Definitely yes/ Rather yes } \\
\text { Hard to tell } \\
\text { Definitely not/ Rather not }\end{array}$ & $\begin{array}{l}360(30.98 \%) \\
104(8.95 \%) \\
698(60.07 \%)\end{array}$ \\
\hline $\begin{array}{l}\text { Do you reach for alcohol in order to de-stress } \\
\text { or discharge negative emotions? } \\
\text { Definitely yes/ Rather yes } \\
\text { Hard to tell } \\
\text { Definitely not/ Rather not } \\
\end{array}$ & $\begin{array}{l}535(46.04 \%) \\
62(5.34 \%) \\
565(48.62 \%) \\
\end{array}$ \\
\hline $\begin{array}{l}\text { Are you religious? } \\
\text { Definitely yes/ Rather yes } \\
\text { Hard to tell } \\
\text { Definitely not/ Rather not }\end{array}$ & $\begin{array}{l}519(44.66 \%) \\
134(11.53 \%) \\
509(43.80 \%)\end{array}$ \\
\hline
\end{tabular}




\section{Adverse Childhood Experiences}

The results of the Adverse Childhood Experiences questionnaire ranged from 0 to 8 with a mean score of 1.23 and median which equaled 1 (interquartile range $0-2) .42 .60 \%$ of the students (n $=495)$ didn't experience any childhood adversity, $24.53 \%(\mathrm{n}=285)$ were affected by 1 childhood adversity, $14.89 \%(\mathrm{n}=173)$ reported an exposure to 2 childhood adversities, $9.55 \%$ $(\mathrm{n}=111)-3$ childhood adversities and $8.43 \%(\mathrm{n}=98)-4$ or more childhood adversities. Overall, more than a half $(\mathrm{n}=667,57.40 \%, 95 \% \mathrm{CI}=54.95-59.85)$ of the participants of the study experienced at least 1 childhood adversity. (Chart 1.) The most common adverse childhood experiences were: emotional neglect $(23.06 \%, \mathrm{n}=268)$, emotional abuse $(22.98 \%$, $\mathrm{n}=267)$ and mental illness or a suicide attempt in a household member $(21.86 \%, \mathrm{n}=254)$. $20.40 \%(n=237)$ of the participants had a household member who abused substances. $16.35 \%$ $(n=190)$ of the students were affected by parental separation or divorce. $7.66 \%(n=89)$ of the respondents experienced physical abuse. 3.7\% $(n=43)$ of the participants of the study were affected by sexual abuse. $3.53 \%(n=41)$ of the participants witnessed violence towards their mother or step-mother. $1.72 \%(\mathrm{n}=20)$ of the students reported being physically neglected. $1.55 \%(\mathrm{n}=18)$ of the respondents had a household member who became imprisoned.

Chart 1. Prevalence of the number of Adverse Childhood Experiences among Polish medical and dental students.

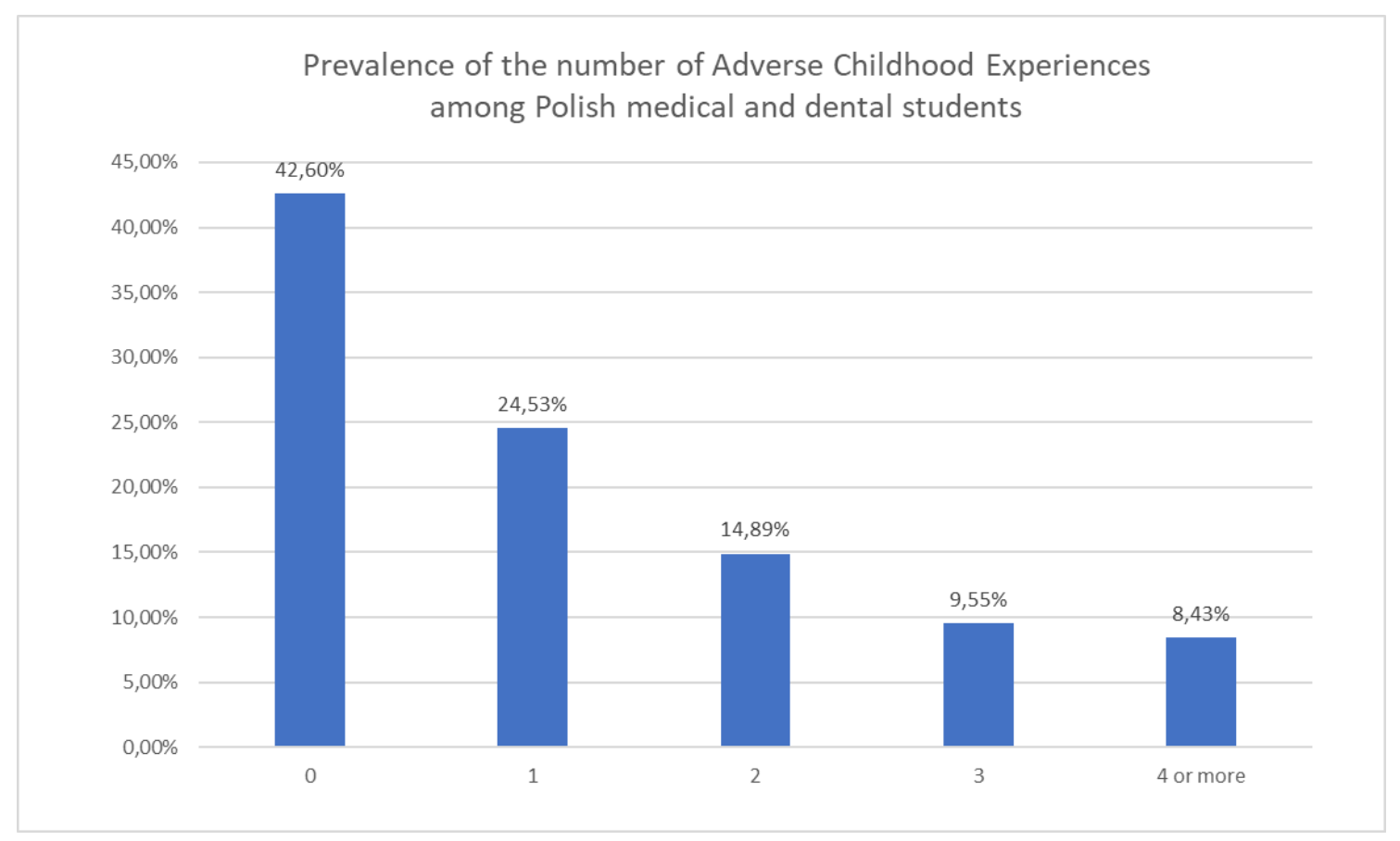

\section{Adverse Childhood Experiences and gender}

On average, women obtained higher scores of Adverse Childhood Experiences questionnaire than men. Among women the average score equaled 1.30, whereas among men - 1.0. Among women $40.25 \%$ of the students $(\mathrm{n}=357)$ didn't experience childhood adversity, $24.80 \%(\mathrm{n}=$ 220) were affected by 1 childhood adversity, $15.67 \%(\mathrm{n}=139)$ reported exposure to 2 childhood adversities, $10.26 \%(n=91)-3$ childhood adversities and $9.02 \%(n=80)-4$ or more childhood 
adversities. Whereas among men $50.18 \%$ of the students $(n=138)$ didn't experience any childhood adversity, 23.64\% $(n=65)$ were affected by 1 childhood adversity, $12.36 \%(n=34)$ reported exposure to 2 childhood adversities, $7.27 \%(\mathrm{n}=20)$ - to 3 childhood adversities and $6.55 \%(\mathrm{n}=18)-$ to 4 or more childhood adversities. (Table 2$)$.

Table 2. Prevalence of the number of Adverse Childhood Experiences according to gender.

\begin{tabular}{|c|c|c|}
\hline $\begin{array}{c}\text { Number of Adverse } \\
\text { Childhood } \\
\text { Experiences }\end{array}$ & $\begin{array}{c}\text { Women } \\
\mathbf{n}(\boldsymbol{\%})\end{array}$ & $\begin{array}{c}\text { Men } \\
\mathbf{n}(\boldsymbol{\%})\end{array}$ \\
\hline $\mathbf{0}$ & $357(40.25 \%)$ & $138(50.18 \%)$ \\
\hline $\mathbf{1}$ & $220(24.80 \%)$ & $65(23.64 \%)$ \\
\hline $\mathbf{2}$ & $139(15.67 \%)$ & $34(12.36 \%)$ \\
\hline $\mathbf{3}$ & $91(10.26 \%)$ & $20(7.27 \%)$ \\
\hline $\mathbf{4}$ or more & $80(9.02 \%)$ & $18(6.55 \%)$ \\
\hline \multicolumn{2}{|c}{} \\
\hline
\end{tabular}

More women than men experienced emotional abuse $(24.24 \%, \mathrm{n}=215$ women and $18.91 \%, \mathrm{n}$ $=52$ men $)$, physical abuse $(7.78 \%, \mathrm{n}=69$ women and $7.27 \%, \mathrm{n}=20 \mathrm{men})$, sexual abuse $(4.51 \%$, $\mathrm{n}=40$ women and $1.09 \%, \mathrm{n}=3$ men $)$ and emotional neglect $(24.69 \%, \mathrm{n}=219$ women $17.82 \%$, $\mathrm{n}=49$ men). Physical neglect was more common among men $(2.55 \%, \mathrm{n}=7)$ than women $(1.47 \%, \mathrm{n}=13)$. Women had a statistically significant higher chance than men of experiencing emotional abuse (OR $=1.37,95 \%$ CI: $0.98-1.93, \mathrm{p}=0.03)$, sexual abuse $(\mathrm{OR}=4.28,95 \%$ CI: $1.31-13.95, \mathrm{p}=0.008)$ and emotional neglect $(\mathrm{OR}=1.51,95 \% \mathrm{CI}=1.07-2.13, \mathrm{p}=$ 0.009). A statistically significant relationship was found between experiencing emotional neglect and female gender. (Table 3).

Table 3. Prevalence of chosen Adverse Childhood Experiences according to gender.

\begin{tabular}{|c|c|c|c|c|c|c|}
\hline & $\begin{array}{c}\text { Women } \\
\mathbf{n}(\%)\end{array}$ & $\begin{array}{c}\text { Men } \\
\mathbf{n}(\%)\end{array}$ & OR & $\mathbf{p}$ & $\chi^{\mathbf{2}}$ & $\mathbf{p}$ \\
\hline Emotional abuse & $\begin{array}{c}215 \\
(24.24 \%)\end{array}$ & $52(18.91 \%)$ & 1.37 & 0.03 & 3.37 & 0.07 \\
\hline Physical abuse & $69(7.78 \%)$ & $20(7.27 \%)$ & 0.08 & 0.78 & 1.08 & 0.39 \\
\hline Sexual abuse & $40(4.51 \%)$ & $3(1.09 \%)$ & 4.28 & 0.008 & - & - \\
\hline Emotional neglect & $\begin{array}{c}219 \\
(24.69 \%)\end{array}$ & $49(17.82 \%)$ & 1.51 & 0.009 & 5.59 & 0.02 \\
\hline Physical neglect & $13(1.47 \%)$ & $7(2.55 \%)$ & 0.57 & 0.12 & 1.45 & 0.23 \\
\hline
\end{tabular}

\section{Factors associated with Adverse Childhood Experiences}

An overall graded relationship was found between Adverse Childhood Experiences and: frequent feelings of loneliness, negative self-assessment of academic performance, having problems with maintaining stable body weight, reaching for alcohol in order to de-stress or discharge negative emotions and being non-religious. (Table 4). 
Table 4. Adverse Childhood Experiences and factors associated with well-being.

\begin{tabular}{|c|c|c|c|c|c|c|}
\hline & \multicolumn{5}{|c|}{ Number of ACEs n (\%) } & \multirow{2}{*}{$\begin{array}{l}\text { Statistical } \\
\text { analysis }\end{array}$} \\
\hline & $\mathbf{0}$ & 1 & 2 & 3 & 4 or more & \\
\hline $\begin{array}{l}\text { Do you often feel } \\
\text { lonely? } \\
\text { Definitely yes/ Rather yes } \\
\text { Hard to tell } \\
\text { Definitely not/ Rather not }\end{array}$ & $\begin{array}{l}173 \\
(34.95 \%) \\
123 \\
(24.85 \%) \\
199 \\
(40.20 \%)\end{array}$ & $\begin{array}{l}114 \\
(40.00 \%) \\
81(28.42 \%) \\
90(31.58 \%)\end{array}$ & $\begin{array}{l}93(53.76 \%) \\
38(21.97 \%) \\
42(24.28 \%)\end{array}$ & $\begin{array}{l}67(60.36 \%) \\
18(16.22 \%) \\
26(23.42 \%)\end{array}$ & $\begin{array}{l}55(56.12 \%) \\
18(18.37 \%) \\
25(25.51 \%)\end{array}$ & $\begin{array}{c}\chi^{2}=47.93 \\
\mathrm{df}=8 \\
p=10^{-7}\end{array}$ \\
\hline $\begin{array}{l}\text { How do you assess your } \\
\text { academic performance? } \\
\text { Very good/ good } \\
\text { Average } \\
\text { Bad/ very bad }\end{array}$ & $\begin{array}{l}258 \\
(52.12 \%) \\
190 \\
(38.38 \%) \\
47(9.49 \%) \\
\end{array}$ & $\begin{array}{l}137 \\
(48.07 \%) \\
122 \\
(42.81 \%) \\
26(9.12 \%) \\
\end{array}$ & $\begin{array}{l}72(41.62 \%) \\
82(47.40 \%) \\
19(10.98 \%)\end{array}$ & $\begin{array}{l}41(36.94 \%) \\
53(47.75 \%) \\
17(15.32 \%)\end{array}$ & $\begin{array}{l}39(39.80 \%) \\
45(45.92 \%) \\
14(14.29 \%)\end{array}$ & $\begin{array}{c}\chi^{2}=16.08 \\
\text { df }=8 \\
p=0.04\end{array}$ \\
\hline $\begin{array}{l}\text { Do you have problems } \\
\text { with maintaining stable } \\
\text { body weight? } \\
\text { Definitely yes/ Rather yes } \\
\text { Hard to tell } \\
\text { Definitely not/ Rather not }\end{array}$ & $\begin{array}{l}125 \\
(25.25 \%) \\
52(16.35 \%) \\
318 \\
(64.24 \%)\end{array}$ & $\begin{array}{l}87(30.58 \%) \\
20(7.02 \%) \\
178 \\
(62.46 \%)\end{array}$ & $\begin{array}{l}63(36.42 \%) \\
15(8.67 \%) \\
95(54.91 \%)\end{array}$ & $\begin{array}{l}48(43.24 \%) \\
7(6.31 \%) \\
56(50.45 \%)\end{array}$ & $\begin{array}{l}37(37.76 \%) \\
10(10.20 \%) \\
51(52.04 \%)\end{array}$ & $\begin{array}{c}\chi^{2}=22.56 \\
\mathrm{df}=8 \\
p=0.004\end{array}$ \\
\hline $\begin{array}{l}\text { Do you reach for } \\
\text { alcohol in order to de- } \\
\text { stress or discharge } \\
\text { negative emotions? } \\
\text { Definitely yes/ Rather yes } \\
\text { Hard to tell } \\
\text { Definitely not/ Rather not }\end{array}$ & $\begin{array}{l}200 \\
(40.40 \%) \\
29(5.86 \%) \\
266 \\
(53.74 \%)\end{array}$ & $\begin{array}{l}128 \\
(44.91 \%) \\
16(5.61 \%) \\
141 \\
(49.47 \%)\end{array}$ & $\begin{array}{l}90(52.02 \%) \\
7(4.05 \%) \\
76(43.93 \%)\end{array}$ & $\begin{array}{l}65(58.56 \%) \\
5(4.50 \%) \\
41(36.94 \%)\end{array}$ & $\begin{array}{l}52(53.06 \%) \\
5(5.10 \%) \\
41(41.84 \%)\end{array}$ & $\begin{array}{c}\chi^{2}=18.19 \\
\mathrm{df}=8 \\
p=0.02\end{array}$ \\
\hline $\begin{array}{l}\text { Are you religious? } \\
\text { Definitely yes/ Rather yes } \\
\text { Hard to tell } \\
\text { Definitely not/ Rather not }\end{array}$ & $\begin{array}{l}257 \\
(51.92 \%) \\
47(9.49 \%) \\
191 \\
(38.59 \%)\end{array}$ & $\begin{array}{l}121 \\
(42.46 \%) \\
34(11.93 \%) \\
130 \\
(45.61 \%)\end{array}$ & $\begin{array}{l}67(38.73 \%) \\
29(16.76 \%) \\
77(44.51 \%)\end{array}$ & $\begin{array}{l}40(36.04 \%) \\
10(9.01 \%) \\
61(54.95 \%)\end{array}$ & $\begin{array}{l}34(34.69 \%) \\
14(14.29 \%) \\
50(51.02 \%)\end{array}$ & $\begin{array}{c}\chi^{2}=26.35 \\
\mathrm{df}=8 \\
p=0.0009\end{array}$ \\
\hline
\end{tabular}

\section{Discussion}

In our study results of the Adverse Childhood Experiences questionnaire had a mean score of 1.23 and a median of 1 . Similar results were obtained in a study carried out among 239 students from a public university in the Midwest with a mean score of 1.1 and a median score of 1.0 [9]. In our analysis $57.4 \%$ of respondents reported at least one ACE exposure and $8.43 \%$ of students 
reported $\geq 4$ exposures. A. F. Sciolla et. al. in a research on the population of 86 third-year medical students of one medical school on the West Coast of the USA obtained similar results: $51 \%$ of them reported at least one ACE exposure. Moreover, all of the students who reported at least four ACEs were women [10]. Whereas a research by Kennedy Amone-P'Olak and Nkalosang K. Letswai on 392 students of the university in Botswana showed that about $73 \%$ of respondents reported one or more ACEs, about $15 \%$ reported 5 or more Adverse Childhood Experiences [11]. According to a research conducted among 48526 adult Americans from 5 states of America, $55.4 \%$ of the respondents reported at least one ACE, whereas $13.7 \%$ of them reported at least 4 ACEs [12].

According to our study the most often reported Adverse Childhood Experience was physical abuse $(23.06 \%$ of respondents) and the least often reported ACE was mental illness in a household member (1.55\% of respondents). In the study by A. F. Sciolla the most often reported ACE was mental illness in household member (29\% of respondents), whereas physical neglect was reported the least often (6\% of respondents) [10]. The most often reported ACE in already mentioned research from Botswana was parental separation or divorce which effected $36.3 \%$ of the students [11]. In a study conducted among 1346 students from Hong Kong, China, Taiwan, and Japan the most often reported ACE was physical abuse - experienced by $28.08 \%$ of students. Respondents also often experienced domestic violence and parental separation, reported respectively by $23.33 \%$ and $19.24 \%$ of the students [13].

Our study enabled to assess a relationship between adverse childhood experiences and gender. The mean ACE score for women was 1.30, whereas the mean ACE score for men was 1.0. A relationship between female gender and increased exposure to adverse childhood experiences was a subject of numerous studies. Similar conclusions were obtained by Andrés F. Sciolla et al. whose research concerned 86 medical students of one medical school on the West Coast of the USA and Beáta Kovács-Tóth et al. studying a population of 516 Hungarian teenagers aged $12-17[10,14]$.

Our study showed that women had a statistically significant higher chance than men of experiencing psychological abuse, sexual abuse and emotional neglect. The available literature provides similar conclusions [10, 14, 15]. Moreover, the research conducted by Andrés F. Sciolla et al. showed a correlation between female gender and higher exposure to physical abuse [10]. In our study also more women than men experienced physical abuse, but this difference is not statistically significant.

Not every research leads to similar conclusions. In an analysis carried out on 737 students from one middle school and one high school located in Seoul in South Korea by E-Jin Park et al., the mean ACE score was higher among men than among women. Furthermore, the mean scores in the physical abuse, sexual abuse and general trauma domains were significantly higher in men than in women [16].

The obtained results indicate a relationship between experiencing ACEs and having problems with maintaining stable body weight. A research conducted in the USA by Lorraine M. McKelvey et al. among 1335 demographically diverse families with low income allowed a conclusion that there is a correlation between ACEs and excess weight defined as having a BMI greater than the $95^{\text {th }}$ percentile [17].

ACE exposure is significantly associated with psychological distress [18]. It is not surprising that the authors' study showed a significant relationship between ACEs and drinking alcohol in order to de-stress or discharge negative emotions. The analysis carried out among 1466 German students by Jascha Wiehn et al. showed a similar relationship. It was found that physical neglect 
has a significant effect on risky drinking, whereas experiencing emotional abuse and peer violence significantly correlate with drug abuse. Moreover, it was proved that experiencing four or more ACEs is associated with smoking, drug abuse, early sexual initiation and having multiple sexual partners [15].

Furthermore, based on a research conducted by Zhihui Jia et al. on a population of 884 senior high school students from Nanchang in China, it can be concluded that ACEs increase the probability of depressive symptoms, suicidal thoughts and suicidal plans [19].

\section{Conclusions}

Adverse Childhood Experiences are common among Polish medical and dental students. $57.40 \%$ of them experienced at least 1 ACE, whereas $8.43 \%$ of them were affected by 4 or more ACEs. The most commonly reported childhood adversities were emotional neglect $(23.06 \%)$, emotional abuse $(22.98 \%)$ and mental illness or a suicide attempt in a household member $(21.86 \%)$. On average, women were affected by more ACEs than men. An overall graded relationship was found between Adverse Childhood Experiences and many aspects of worsened well-being in adult life of the students, such as: frequent feelings of loneliness, negative selfassessment of academic performance, having problems with maintaining stable body weight, reaching for alcohol in order to de-stress or discharge negative emotions and being nonreligious. Our study emphasizes the importance of implementing strategies that aim to educate on Adverse Childhood Experiences in order to prevent them and help those who are affected by them.

\section{References}

[1] Gilgoff R, Singh L, Koita K, Gentile B, Marques SS. Adverse Childhood Experiences, Outcomes, and Interventions. Pediatr Clin North Am. 2020 Apr;67(2):259-273. doi: 10.1016/j.pcl.2019.12.001. PMID: 32122559.

[2] Bucci M, Marques SS, Oh D, Harris NB. Toxic Stress in Children and Adolescents. Adv Pediatr. 2016 Aug;63(1):403-28. doi: 10.1016/j.yapd.2016.04.002. PMID: 27426909.

[3] Kalmakis KA, Chandler GE. Health consequences of adverse childhood experiences: a systematic review. J Am Assoc Nurse Pract. 2015 Aug;27(8):457-65. doi: 10.1002/23276924.12215. Epub 2015 Mar 5. PMID: 25755161.

[4] Hughes K, Bellis MA, Hardcastle KA, Sethi D, Butchart A, Mikton C, Jones L, Dunne MP. The effect of multiple adverse childhood experiences on health: a systematic review and metaanalysis. Lancet Public Health. 2017 Aug;2(8):e356-e366. doi: 10.1016/S24682667(17)30118-4. Epub 2017 Jul 31. PMID: 29253477.

[5] Liu Y, Croft JB, Chapman DP, Perry GS, Greenlund KJ, Zhao G, Edwards VJ. Relationship between adverse childhood experiences and unemployment among adults from five U.S. states. Soc Psychiatry Psychiatr Epidemiol. 2013 Mar;48(3):357-69. doi: 10.1007/s00127-012-05541. Epub 2012 Aug 7. PMID: 22869349; PMCID: PMC4539022.

[6] Gilbert R, Widom CS, Browne K, Fergusson D, Webb E, Janson S. Burden and consequences of child maltreatment in high-income countries. Lancet. 2009 Jan 
3;373(9657):68-81. doi: 10.1016/S0140-6736(08)61706-7. Epub 2008 Dec 4. PMID: 19056114.

[7] Hughes K, Bellis MA, Hardcastle KA, Sethi D, Butchart A, Mikton C, Jones L, Dunne MP. The effect of multiple adverse childhood experiences on health: a systematic review and metaanalysis. Lancet Public Health. 2017 Aug;2(8):e356-e366. doi: 10.1016/S24682667(17)30118-4. Epub 2017 Jul 31. PMID: 29253477.

[8] Makaruk K, Włodarczyk J, Sethi D, Michalski P, Szredzińska R, Karwowska P. Survey of adverse childhood experiences and associated health-harming behaviours among Polish students. 2018.

[9] Karatekin C. Adverse Childhood Experiences (ACEs), Stress and Mental Health in College Students. Stress Heal. 2018;34(1):36-45. doi: 10.1002/smi.2761. PMID: 28509376.

[10] Sciolla AF, Wilkes MS, Griffin EJ. Adverse Childhood Experiences in Medical Students: Implications for Wellness. Acad Psychiatry. 2019; 43(4): 369-374. doi: 10.1007/s40596-01901047-5. PMID: 30850989.

[11] Amone-P'olak K, Letswai NK. The relationship between adverse childhood experiences and depression: A cross-sectional survey with university students in Botswana. South African J Psychiatry. 2020;26:1-8. doi: 10.4102/sajpsychiatry.v26i0.1444. PMID: 33240547

[12] Campbell JA, Walker RJ, Egede LE. Associations Between Adverse Childhood Experiences, High-Risk Behaviors, and Morbidity in Adulthood. Am J Prev Med. 2016 Mar;50(3):344-352. doi: 10.1016/j.amepre.2015.07.022. Epub 2015 Oct 21. PMID: 26474668.

[13] Ho GWK, Bressington D, Karatzias T, Chien WT, Inoue S, Yang PJ, et al. Patterns of exposure to adverse childhood experiences and their associations with mental health: a survey of 1346 university students in East Asia. Soc Psychiatry Psychiatr Epidemiol [Internet]. 2020;55(3):339-49. Available from: https://doi.org/10.1007/s00127-019-01768-w

[14] Kovács-Tóth B, Oláh B, Papp G et al. Assessing adverse childhood experiences, social, emotional, and behavioral symptoms, and subjective health complaints among Hungarian adolescents. Child Adolesc Psychiatry Ment Health. 2021; 15: 12. doi: 10.1186/s13034-02100365-7. PMID: 33618739.

[15] Wiehn J, Hornberg C, Fischer F. How adverse childhood experiences relate to single and multiple health risk behaviours in German public university students: a cross-sectional analysis. BMC Public Health. 2018; 18: 1005. doi: 10.1186/s12889-018-5926-3. PMID: 30103728.

[16] Park EJ, Kim SY, Kim Y et al. The Relationship between Adverse Childhood Experiences and Sleep Problems among Adolescent Students: Mediation by Depression or Anxiety. Int J Environ Res Public Health. 2021 Jan; 18(1): 236. doi: 10.3390/ijerph18010236. PMID: 33396920.

[17] McKelvey LM, Saccente JE, Swindle TM. Adverse Childhood Experiences in Infancy and Toddlerhood Predict Obesity and Health Outcomes in Middle Childhood. Child Obes. 2019 Apr 1; 15(3): 206-215. doi: 10.1089/chi.2018.0225. PMID: 30762431.

[18] Agbaje OS, Nnaji CP, Nwagu EN et al. Adverse childhood experiences and psychological distress among higher education students in Southeast Nigeria: an institutional-based crosssectional study. Arch Public Health. 2021; 79: 62. doi: 10.1186/s13690-021-00587-3. PMID: 33926542. 
[19] Jia Z, Wen X, Chen F et al. Cumulative Exposure to Adverse Childhood Experience: Depressive Symptoms, Suicide Intensions and Suicide Plans among Senior High School Students in Nanchang City of China. Int J Environ Res Public Health. 2020 Jul; 17(13): 4718. doi: 10.3390/ijerph17134718. PMID: 32630073. 